\title{
A MIXED-INTEGER PROGRAMMING MODEL FOR THE JOB SCHEDULING PROBLEM IN A PRODUCTION COMPANY
}

\author{
Durdu Hakan UTKU ${ }^{1}$, Karanfil ÖZYiĞiT² ${ }^{2}$, Esra Yağmur FARiZOĞLU³
}

\begin{abstract}
Purpose: In this study, a mixed-integer programming model is developed to minimize the total lateness and total completion time of the jobs in an automotive company. In order to respond rapidly to the continuous customer demand through the production, the work schedule of engineers in the research and development department is considered flexibly.

Methodology: In the study, the mixed-integer programming model is supported by the analytical hierarchy process model to determine the weighted values of total tardiness and total completion times. The developed model is applied to the automotive company using the real data and the problem is solved using the GAMS CPLEX 24.1.3 software.
\end{abstract}

Findings: In this job scheduling problem, the total completion time is decreased to 622 hours from 10149 hours, maximum tardiness is decreased to 9 hours from 104 hours and total tardiness is decreased to 13 hours from 860 hours by using the proposed model.

Originality: The proposed model is used for the job scheduling purpose in compliance with the structure of the automotive industry company using the machine scheduling modeling principles and Analytical Hierarchy Process together.

Keywords: Parallel Machine Scheduling, Optimization, Mixed Integer Programming, Analytical Hierarchical Process.

JEL Codes: C60, C61, C63.

\section{BíR ÜRETIM FIRMASINDA iş ÇizeLGELEME PROBLEMI IÇiN BİR TAM SAYILI PROGRAMLAMA MODELI \\ ÖZET}

Amaç: Bu çalışmada, bir otomotiv firmasındaki işlerin toplam gecikmesini ve toplam tamamlanma süresini en aza indirmek amacıyla karma tamsayılı bir programlama modeli geliştirilmektedir. Üretim yoluyla sürekli müşteri talebine hızlı cevap verebilmek için, araştırma ve geliştirme departmanındaki mühendislerin çalışma programı esnek olarak değerlendirilmektedir.

Yöntem: Yapılan çalışmada, karma tamsayı programlama modeli, toplam gecikme ve toplam tamamlanma sürelerinin ağırlıklı değerlerini belirlemek için analitik hiyerarşi süreç modeli tarafından desteklenmektedir. Geliştirilen model, gerçek veriler kullanılarak otomotiv firmasına uygulanmakta ve problem GAMS CPLEX 24.1.3 yazılımı kullanılarak çözülmektedir.

Bulgular. Bu iş çizelgeleme probleminde önerilen model kullanılarak, toplam tamamlanma süresi 10149 saatten 622 saate, maksimum gecikme süresi 104 saatten 9 saate ve toplam geç tamamlanma süresi 860 saatten 13 saate düşürülmektedir.

Özgünlük: Önerilen model söz konusu otomotiv endüstrisi firmasının yapısına özgün olarak, makine çizelgeleme modelleme esaslarının ve Analitik Hiyerarşi Prosesinin birlikte iş çizelgelemesi amacıyla kullanılmaktadır.

Anahtar Kelimeler. Paralel Makine Çizelgeleme, Optimizasyon, Karışık Tamsayılı Programlama, Analitik Hiyerarşi Prosesi.

JEL KodlarI: C60, C61, C63.

\footnotetext{
${ }^{1}$ Asst. Prof. Dr., University of Turkish Aeronautical Association, Industrial Engineering Department, Ankara, Turkey, dhutku@thk.edu.tr, ORCID: 0000-0002-5755-6101 (Corresponding Author).

2 Industrial Engineer, University of Turkish Aeronautical Association, Industrial Engineering Department, Ankara, Turkey, karanfilozyigit@gmail.com, ORCID: 0000-0001-7323-3102.

3 Industrial Engineer, University of Turkish Aeronautical Association, Industrial Engineering Department, Ankara, Turkey, yagmurrf@gmail.com, ORCID: 0000-0001-7735-6329.
} 


\section{INTRODUCTION}

Companies have to use all their resources optimally, in order to be successful in a competitive environment. One of the important approaches in recent years is the use of human resources and labor force effectively with the effective use of the workforce to achieve productivity. In this way, the quality level can be increased, and a competitive advantage might be achieved. Scheduling plays an important role while accomplishing this.

For different production environments in the industry, parallel machine scheduling problems are commonly used to minimize the manufacturing time in different production environments. Most of the studies in the literature consider that most of the parameters of the problem are known before the manufacturing procedures start. But, after the real situation is observed, the results of the deterministic assumptions may cause the solutions to be significantly different from the realized ones (Hu et al., 2016).

In most manufacturing companies, the primary concern is the production environment and the effectiveness of the planning procedures related to these activities. In every department of the companies, there are different planning necessities. It is apparent that optimization of the crew job scheduling is another area of interest in these organizations.

In this study, different from the literature, as a contribution, modeling processes that are used for the scheduling of the production systems, are used for the scheduling of the jobs for the engineers. We apply as if the engineers in the Research and Development (R\&D) department are parallel machines and jobs that are assigned to the engineers are the jobs determined that the engineers are to be assigned. A mixedinteger programming model is used for the scheduling of the jobs and an Analytical Hierarchy Process (AHP) model is used to determine the weights for the total delay time and total completion time specified that are used in the mixed-integer programming model. The mixed-integer programming model enables the parallel machine scheduling model for the solution of the job assignment of the engineers according to the priority of the decision-maker. The objective is to minimize the total tardiness and total completion time for the necessary modifications on the products according to the customer orders. With the developed model, the total tardiness and total completion time are considered for the parallel identical machine scheduling problem to assign the engineers jobs.

The methodology that is used fosters the productivity of the company by improving the total completion time, maximum tardiness time, total tardiness time, and the number of works in tardiness. By the improvement of these performance measurements, high customer satisfaction and an increase in profits motivate the use of the developed model that increases the productivity of the company in concern.

In the study, the jobs in the specified period and the delayed jobs in previous periods are taken into account. The reason for selecting these periods is to be able to actively observe products on the production line during the period. The changes on the products to be worked on by the engineers in the $R \& D$ department between the predetermined dates have been considered in the developed model. Besides, there are extra jobs that create bottlenecks, which should be finished in the previous periods during these periods but are forced to work in these periods due to customer request changes, production errors, etc. These changes are handled along with the works in the normal periods. At the same time, separate workloads are identified for each of these changes. The works observed during this period are assigned to the engineers.

The remainder of the study is structured as follows: Literature survey is in Section 2. The problem definition and methodology are in Section 3. The results and discussion of the problem considering the developed models are presented in Section 4. Finally, the conclusions are discussed in Section 5.

\section{LITERATURE SURVEY}

In the previous studies, scheduling has been applied for unrelated parallel machines considering this type of problem. The performance criteria considered are the total completion time and maximum tardiness criteria, which are important in scheduling. Liaw et al. (2003) developed a model that minimizes the total weighted tardiness for a set of jobs to be scheduled on unrelated parallel machines. Because this type of problem is in the class of NP-hard problems, they introduce a branch-and-bound algorithm that uses different rules together with effective lower and upper bounds to be able to find an optimal solution. Different from the unrelated parallel machines, Lenstra et al. (1990) deal with parallel machines and independent jobs to identify a program that minimizes construction time by using approximation algorithms, worst-case analysis, linear programming, integer programming. Also, Yalaoui and Chu (2002) study the identical parallel machine scheduling problem that minimizes total tardiness. To cut off the search tree, control properties are stated and upper and lower limiting methods are proposed. They introduce a branch and 
bound algorithm and test it by using different medium-sized generated problems by considering these theoretical features, upper and lower bounds.

Eck and Pinedo (1993), Gupta et al. (2000) study the maximum completion time and total completion time in two-machine cases in multi-criteria parallel machine systems. Gupta and Ruis-Torres (2000) and Lin and Liao (2004) develop solution approaches in the m-machine case. Mohri et al. (1999) examine the maximum completion time and maximum delay criteria for the three-machine case and Suresh and Chaudhuri (1996) for the m-machine case. Sarin and Hariharan (2000) discuss the problem of minimizing the maximum delay and the number of delayed jobs. The branch-and-bound method is used in their studies. They develop heuristic approaches in large-scale problems. Kasımoğlu et al. (2021) introduce a mixedinteger programming model with sequence-dependent setup times in order to solve the extra jobs in the production process problem that exists in the dye house department of a white goods manufacturing company.

Two identical criterion parallel machine scheduling problem is examined in the study of Eren and Güner (2008). The objective function of the problem is to minimize the total completion time and the weighted sum of the maximum tardiness. It is aimed to reduce tardiness to a minimum level and number by performing work scheduling of engineers in the R\&D department by assuming the engineers are parallel machines.

In our proposed model an AHP study is used to weigh the two specified criteria for this purpose. In the literature, we see that AHP can be used in all decision-making situations. Thus we aim to increase the efficiency and quantify the data by using AHP methodology together with scheduling.

Kurttila et al. (2000) use a Strengths, Weaknesses, Opportunities, Threats (SWOT) analysis that is integrated with AHP in order to use SWOT analysis more effectively in their studies. This method provides to determine the priorities analytically for the factors included in the SWOT analysis and made them measurable. Here, the main purpose of the application of AHP method is to improve the quantitative knowledge base of strategic planning processes. Dağdeviren and Yüksel (2008) examine the issue of occupational safety with an AHP approach that allows both multi-criteria and simultaneous evaluation. Wong and Li (2008) apply AHP to the multi-criteria analysis of the selection of smart building systems. For this, they propose a two-stage questionnaire. Thus, they contributed to understanding the selection criteria of the systems and seeing their importance.

Lee and Kozar's (2006) study tries to obtain the highest quality website that is produced with the highest business performance through their AHP approach study. In the study by Improta et al. (2019) that is applied to the healthcare sector, two methods are used in the assessment for the decision-maker to identify the most valuable service features and to determine user satisfaction and possible service improvements: AHP and the Likert scale. The application of the methods provided the necessary information to improve the service quality. Petruni et al. (2019) apply AHP to select the appropriate human factors technique in their studies. They used this method to select the appropriate human reliability analysis technique for the automotive industry, which is not widely used.

In a case study of Charchi et al. (2018), a Geographic Information System (GIS) is used with AHP techniques for Remote sensing (RS) in order to identify the groundwater potential zones, in the LeyliaKeynow basin in southwestern Iran. It can be said that AHP contributes to the main study rather than being used alone, based on the studies of the recent years that can be reproduced such as Younas et al. (2019) and Zheng et al. (2019).

Similar to the studies, Liaw et al. (2003), Yalaoui and Chu (2002) Mohri et al. (1999), and Eren and Güner (2008), we have the objective of minimizing the total tardiness and total completion time. They all use scheduling methodology for machine scheduling purposes. But, different from the literature, as a contribution, we use AHP as an auxiliary model that helps to determine the weights for the total delay time and total completion time specified in the model while considering the parallel machine scheduling model for the solution to the job assignment of the engineers according to the priority of the decision-maker. In this way, the developed model goes beyond the classical usage of scheduling and AHP methodology. We use mixed integer programming for the scheduling model and AHP methodology together for the job and engineers by using real data.

\section{PROBLEM DEFINITION and METHODOLOGY}

In this section, we define the problem and we use AHP and mixed-integer programming model for the solution of the problem. AHP model is used to determine the weights for the total delay time and total completion time specified in the mixed-integer programming model for scheduling the job assignment of the engineers for the R\&D department of the company. 


\subsection{Problem Definition}

In this study, the work scheduling of engineers in the research and development (R\&D) department is determined to respond more flexibly to the rapidly changing customer demands. As an objective, a parallel machine scheduling model is developed to minimize the total tardiness and total completion time for implementing the necessary modifications on the products according to the customer orders in the mechanical R\&D department of the company. In the R\&D department, the mechanical design of "Vehicle Type 1", "Vehicle Type 2" and "Vehicle Type 3" (city, travel, and medium-distance buses) are realized. According to the sales department's direction based on the customer demand, the products are checked to determine the design requirements. The required changes are listed. As a result of the different demand requirements of each customer, the necessary working hours required for the jobs are determined. These listed jobs are performed independently of each other with the priority of the work before the delivery date. In the current situation of the company, the jobs that are assigned to the engineers in the department have different workloads and the jobs are not arriving in a certain order. Additionally, the jobs have different delivery dates that cause job delays. In the existing process, the job assignment to engineers is done manually on an Excel sheet and cannot be distributed equally to engineers. The negative effects of these problems create additional costs for the company. Additionally, the delays cannot be controlled and the active progress of the work cannot be monitored during the delivery period.

In the mechanical R\&D department, this process is complex, and it is observed that there are work delays due to the need for different working times and irregular arrival of the works. The delays in the mechanical R\&D department are the core problems for the developed model to be solved. Due to the lack of a standard workflow, it is not possible to keep the assignment of the works they have done via Excel sheet up to date. Currently, engineers are assigned to jobs manually and jobs cannot be distributed evenly to employees, which creates additional costs for the enterprise. Delays cannot be controlled as the active progress of the job cannot be observed during delivery time. Additionally, mechanical design works of the vehicles cannot be carried out on the prescribed delivery dates, or overtime is carried out in order to release the vehicles to production on the specified deadlines.

The bus types worked on in the R\&D department are mainly three types of vehicles, Vehicle Type 1 , Vehicle Type 2, and Vehicle Type 3. These bus types have different planning periods. All vehicle types have a total of 36 periods for one year. The start and end dates of the periods are different for each bus.

\subsection{AHP Model}

AHP procedure is a multi-criteria decision-making method developed by Saaty (1977). AHP emphasizes how important are the criteria and decision choices by pairwise comparisons. The data can be obtained from experimental or real measurements such as price, weight, etc., or subjective ideas such as satisfaction feelings, and choices (Teknomo, 2006: 9).

In this study, AHP model is implemented to determine the total delay time and total completion time specified in the model. The criteria that affect the total completion time and total delay times are determined. These criteria are as follows:

For the total completion time;

- Early notification of orders from the purchasing department,

- Notification of change in customer requests early,

- Accelerated by receiving special training on the subject of the engineer who will work.

For the total tardiness time;

- Engineer activity,

- Reduction of special permissions,

- Over time,

- Precautions that are taken for unexpected conditions (natural disasters, outbreaks, etc.).

A questionnaire is submitted to the decision-makers to compare the predetermined criteria in pairs. The decision-makers are asked to score points for each question, taking into account the following weighting in Table 1. As a result of the questionnaire, we obtained the weights that are stated in Table 2. 


\begin{tabular}{cl} 
Table 1. & Scale of relative importance \\
\hline $\begin{array}{c}\text { Intensity of } \\
\text { Importance }\end{array}$ & Definition \\
\hline 1 & Equal importance \\
2 & Weak \\
3 & Moderate importance \\
4 & Moderate plus \\
5 & Strong importance \\
6 & Strong plus \\
7 & Very strong or demonstrated importance \\
8 & Very very strong \\
9 & Extreme importance \\
\hline
\end{tabular}

Senior managers and engineers have filled the questionnaire. Questionnaire results are evaluated using Web-HIPRE (Table 2). In Table 2, the weights of the total completion time and the total tardiness time are shown for each criterion.

Table 2. Weights obtained according to the questionnaire results for each criterion

\begin{tabular}{clcc}
\hline No & Criteria & $\begin{array}{c}\text { Weight of Total } \\
\text { Completion Time }\end{array}$ & $\begin{array}{c}\text { Weight of Total } \\
\text { Tardiness Time }\end{array}$ \\
\hline 1 & $\begin{array}{l}\text { Early Notification of Orders from the } \\
\text { Purchasing Department }\end{array}$ & 0,032 & 0 \\
2 & $\begin{array}{l}\text { Notification of Change in Customer Requests } \\
\text { Early }\end{array}$ & 0,340 & 0 \\
& Accelerated by receiving special training on & 0,256 & 0 \\
3 & the subject of the engineer who will work & 0 & 0,182 \\
4 & More Active Engineers & 0 & 0,096 \\
5 & Reduction of Special Permissions & 0 & 0,054 \\
6 & Overtime & 0 & 0,040 \\
7 & $\begin{array}{l}\text { Precautions Taken for Unexpected Conditions } \\
\text { (natural disasters, outbreaks, etc.) }\end{array}$ & 0,628 & 0,372 \\
\hline Total & &
\end{tabular}

\subsection{Mathematical Model}

A mixed-integer programming model is developed for the problem of job assignment of the engineers in the company. It is assumed that the processing time $p_{j i}$ and the delivery date $d_{j}$ are known in advance. The engineers are assumed to be as if they are machines and the jobs are assumed to be the jobs that are processed in these machines.

\subsubsection{Notations}

Parameters

$n$ : Number of jobs,

$$
j=1,2, \ldots, n
$$

$m$ : Number of machines,

$\alpha$ : Weight of total completion time, $\alpha \geq 0$

$\beta$ : Weight of maximum delay, $\alpha+\beta=1$

$p_{j i}$ : Processing time of the job $j$ that assigned to machine $i, \quad j=1,2, \ldots . n \quad i=1,2, \ldots, m$

$d_{j}$ : Delivery date for job $j, \quad j=1,2, \ldots, n$

$n_{i}$ : Number of jobs on the machine $i,\left(\sum_{i=1}^{m} n_{i}=n\right) \quad i=1,2, \ldots, m$

Variables

$x_{j i k}:\left\{\begin{array}{cc}1, \text { Ifassigning the job } j \text { to the machine } i \text { with the order } k \\ 0, & \text { Otherwise }\end{array}\right.$

$i=1,2, \ldots, m, j=1,2, \ldots, n . k=1,2, \ldots, n_{i}$ 
$p p_{k i}$ : Processing time of the job that assigned to machine $i$ with order $k, i=1,2 \ldots \ldots m, k=1,2, \ldots, n_{i}$

$c_{k i}$ : Completion time of the job assigned to machine $i$ with order $k, i=1,2 \ldots \ldots, k=1,2, \ldots, n_{i}$

$d_{i k}^{*}:$ The delivery date of the job that assigned to machine $i$ with order $k, i=1,2 \ldots \ldots m, k=1,2, \ldots, n_{i}$

$T_{\text {max }}$ : Maximum tardiness

\subsubsection{Mixed Integer Programming Model}

\section{Objective Function}

$\operatorname{Min} \alpha \sum c_{k i}+\beta T_{\max }$

Constraints

$p p_{k i}=\sum_{j=1}^{n} x_{j i k} p_{j i}$

$i=1,2, \ldots, m, k=1,2, \ldots, n_{i}$

$c_{k i}=p_{1 i}$

$i=1,2, \ldots, m, k=1,2, \ldots, n_{i}$

$c_{k i} \geq c_{k-1, i}+p p_{k i}$

$k=1,2, \ldots, n_{i}, i=1,2, \ldots, m$

$d_{i k}^{*}=\sum_{j=1}^{n} x_{j i k} d_{j}$

$i=1,2, \ldots, m, k=1,2, \ldots, n_{i}$

$T_{\text {max }} \geq c_{k i-} d_{i k}^{*}$

$i=1,2, \ldots, m, k=1,2, \ldots, n_{i}$

$\sum_{j=1}^{n} x_{i j k}=1$

$k=1,2, \ldots, n_{i}, \quad i=1,2, \ldots, m, j=1,2, \ldots, n$

$\sum_{i=1}^{m} \sum_{k=1}^{n_{j}} x_{j i k}=1$

$j=1,2, \ldots, n$

$p p_{k i}, c_{k i}, d_{i k}^{*} \geq 0$

$i=1,2, \ldots, m, k=1,2, \ldots, n_{i}$

$x_{j i k} \in\{0,1\}$

$i=1,2, \ldots, m, j=1,2, \ldots, n . k=1,2, \ldots, n_{i}$

In the model, the objective function (Equation 1) minimizes the total weighted completion and total weighted delay time. An AHP model is used to determine the weights of the total completion time $(\alpha)$ and maximum delay time $(\beta)$, with the participation of engineers working in this department.

Equation 2 calculates the $p p_{k i}$, the processing time of the job that is assigned to machine $i$ with order $k$. Equation 2 calculates the processing time of the job assigned to machine $i$ with order $k$. The Equation 3 equates the completion time of the job assigned to machine $i$ with order $k$ to the processing time of the job that assigned to machine 1 with order $k$, Equation 4 determines the $c_{k i}$, the completion time of the job that is assigned to machine $i$ with order $k$. Equation 5 finds the $d_{i k}^{*}$, the delivery date of the job that is assigned to machine $i$ with order $k$. Equation 6 is the maximum tardiness constraint. Equations 7 and 8 ensure that a single job is assigned to each position for each machine. Equation 9 is the nonnegativity constraint and Equation 10 is $(0-1)$ constraint.

\section{COMPUTATIONAL RESULTS}

Processing times and delivery dates for 62 jobs assigned by the assignment model are given in Table 3. For each of the engineers, the processing times and the delivery dates are stated. By using these parameters, the jobs are scheduled for 20 engineers with the proposed scheduling model using GAMS CPLEX 24.1.3. 
Table 3. The jobs $(j)$, processing times for each job for each engineer $\left(p_{j i}\right)$, and delivery dates for the jobs $\left(d_{j}\right)$

\begin{tabular}{ccccccccc}
\hline$j$ & $p_{j i}$ & $d_{j}$ & $j$ & $p_{j i}$ & $d_{j}$ & $j$ & $p_{j i}$ & $d_{j}$ \\
\hline 1 & 4 & 48 & 22 & 8 & 448 & 43 & 40 & 48 \\
2 & 2 & 48 & 23 & 8 & 448 & 44 & 6 & 48 \\
3 & 8 & 48 & 24 & 4 & 64 & 45 & 15 & 48 \\
4 & 6 & 48 & 25 & 4 & 144 & 46 & 6 & 192 \\
5 & 12 & 72 & 26 & 7 & 344 & 47 & 1 & 192 \\
6 & 5 & 48 & 27 & 7 & 344 & 48 & 18 & 368 \\
7 & 3 & 48 & 28 & 11 & 344 & 49 & 10 & 608 \\
8 & 3 & 96 & 29 & 11 & 344 & 50 & 10 & 608 \\
9 & 3 & 48 & 30 & 7 & 344 & 51 & 30 & 608 \\
10 & 3 & 48 & 31 & 9 & 144 & 52 & 8 & 368 \\
11 & 15 & 48 & 32 & 9 & 64 & 53 & 7 & 368 \\
12 & 40 & 136 & 33 & 3 & 48 & 54 & 8 & 376 \\
13 & 4 & 48 & 34 & 20 & 464 & 55 & 6 & 192 \\
14 & 20 & 24 & 35 & 6 & 256 & 56 & 10 & 192 \\
15 & 4 & 448 & 36 & 5 & 440 & 57 & 9 & 48 \\
16 & 11 & 448 & 37 & 12 & 48 & 58 & 9 & 240 \\
17 & 9 & 448 & 38 & 9 & 48 & 59 & 12 & 240 \\
18 & 7 & 448 & 39 & 20 & 48 & 60 & 18 & 240 \\
19 & 15 & 48 & 40 & 4 & 48 & 61 & 18 & 240 \\
20 & 8 & 344 & 41 & 10 & 48 & 62 & 9 & 240 \\
21 & 4 & 1408 & 42 & 12 & 384 & & & \\
\hline
\end{tabular}

The results found when the problem is solved with the proposed model are given in Table 4. In Table 4 and Figure 1, the jobs assigned to 20 engineers are shown. According to the results, except for Engineer 13 and Engineer 19 that are assigned 4 jobs, the other engineers are assigned 3 jobs achieving an objective value of 618.788 hours with $T \_$max $=9$ hours.

Table 4. The Jobs that are assigned by the model. GAMS Model output results for $(\alpha=0,628, \beta=0,372)$

\begin{tabular}{cccccccccc}
\hline EngineerlOrder & 1 & 2 & 3 & 4 & Engineer|Order & 1 & 2 & 3 & 4 \\
\hline 1 & 55 & 26 & 39 & 11 & 36 & 50 & 19 & \\
2 & 44 & 57 & 60 & 12 & 24 & 20 & 59 & \\
3 & 4 & 41 & 28 & 13 & 47 & 30 & 49 & 56 \\
4 & 7 & 32 & 29 & 14 & 1 & 52 & 43 & \\
5 & 13 & 27 & 42 & 15 & 33 & 3 & 48 \\
6 & 25 & 38 & 12 & 16 & 10 & 18 & 45 \\
7 & 35 & 22 & 37 & 17 & 9 & 58 & 61 \\
8 & 8 & 23 & 51 & 18 & 15 & 17 & 14 \\
9 & 6 & 31 & 11 & 19 & 2 & 46 & 54 & 5 \\
10 & 21 & 53 & 16 & 20 & 40 & 62 & 34 & \\
\hline
\end{tabular}

Note: $z=618,788, \operatorname{Tmax}=9$ 


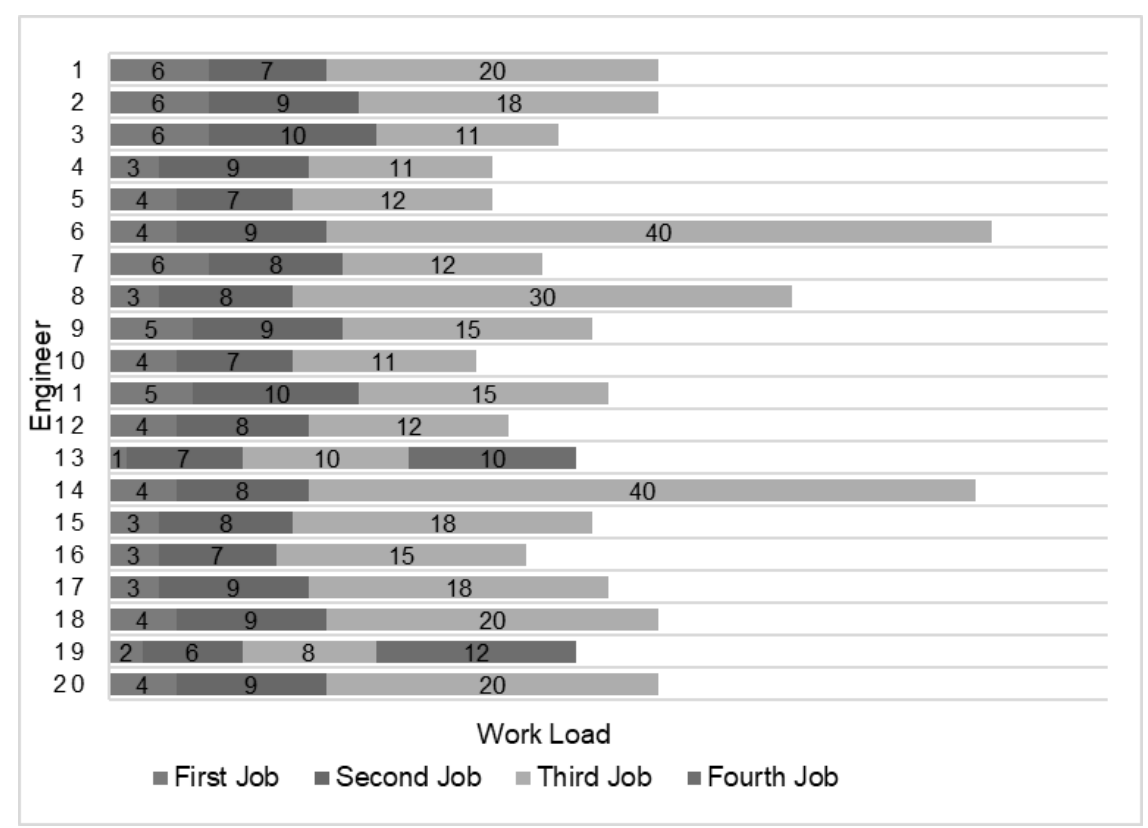

Figure 1. Gantt Chart for $(\alpha=0,628, \beta=0,372)$

In the existing situation, although the delivery dates and the current capacity of the employees are tried to be taken into consideration while the jobs are being distributed, the jobs are distributed unevenly to the employees. Jobs that are very close to the delivery date are accumulated in certain individuals and this causes delays in jobs. As a result, it can be said that, with the existing job allocation way, the jobs that are close to the delivery date are assigned to certain employees whose jobs are not distributed in a balanced way that cause delays in jobs. But as in Table 5, it is apparent that the improvement for each of the criteria is significantly high. For the productivity of the engineers employed, there exists important improvement in the company. With the proposed model, the delays are minimized which means an increase in customer satisfaction. It is apparent that there are improvements in the percentage of recovery of total completion time, maximum tardiness time, and the number of works in tardiness, \%93,87, \%91,34. \%98,48 and 90,9, respectively.

Table 5. Comparison of the current status and scheduled status

\begin{tabular}{lccc}
\hline Criteria & Existing & After Scheduling & $\begin{array}{c}\text { Percentage of } \\
\text { Recovery }\end{array}$ \\
\hline Total completion time (hour) & 10149 & 622 & 93,87 \\
Maximum tardiness time (hour) & 104 & 9 & 91,34 \\
Total tardiness time (hour) & 860 & 13 & 98,48 \\
Number of works in tardiness & 22 & 2 & 90,9 \\
\hline
\end{tabular}

\section{CONCLUSION}

In this study, an AHP and a mixed-integer programming model are developed for the job assignment of engineers in the Mechanical R\&D department of a company in the automotive industry. The objective is to minimize the total tardiness and total completion time for the necessary modifications on the products according to the customer orders. With the developed model, the total tardiness and total completion time are considered for the parallel identical machine scheduling problem to assign the engineers jobs. Each of them is assigned a weight $(\alpha=0,628$ and $\beta=0,372)$ by using AHP method considering seven criteria. By using these weights, the mixed-integer programming model is applied to the problem. With the solution of the problem, \%93,87, \%91,34, \%98,48, and \%90,9 improvements are obtained in the total completion time, maximum tardiness time, total tardiness time, and the number of works in tardiness, respectively.

Different from the literature, modeling processes are run as if they are on parallel machines and an AHP model is used to determine the weights for each criterion. In this study, jobs are assigned to the engineers by considering as if the engineers in the $R \& D$ department are parallel machines. As a contribution to the literature, we use AHP as an auxiliary model that helps to determine the weights for the total delay time and total completion time specified in the model while considering the parallel machine scheduling model for the solution to the job assignment of the engineers according to the priority of the decision-maker. In this way, the developed model goes beyond the classical usage of scheduling and AHP methodology. 
The improvements that are obtained in the total completion time, maximum tardiness time, total tardiness time, and the number of works in tardiness foster productivity in the company with the effective use of the engineers. Thus, high satisfaction of the customers and an increase in profits is promoted by the use of the developed model. The developed model is a useful tool for the decision-makers to increase the effectiveness of the companies by efficient allocation of resources.

The basic limitation of the developed model is the size of the problem. Because this type of problem is in the class of NP-hard problems (Liaw et al. 2003), as the number of engineers and jobs increases, the solution of the problem gets harder. As a future study, metaheuristics or problem-specific heuristics can be developed for the cases in which large-scale companies and the problems related to them are considered. The heuristics may enable the user to solve the problems in a considerable time duration. 


\section{REFERENCES}

Charchi, N. Kalantari, Mehrabi Nejad, A. and Karimi Vardanjani, H. (2018). "Delineation of Groundwater Potential Zones Using Remote Sensing (RS), Geographical Information System (GIS) and Analytic Hierarchy Process (AHP) Techniques: A Case Study in the Leylia-Keynow Watershed, Southwest of Iran", Carbonates and Evaporites, 34,1307-1319.

Dağdeviren, M. and Yüksel, İ. (2008). "Developing a Fuzzy Analytic Hierarchy Process (AHP) Model for BehaviorBased Safety Management”, Information Sciences, 178(6), 1717-1733.

Eck, B.T. and Pinedo, M. (1993). "On the Minimization of the Makespan Subject to Flowtime Optimality", Operations Research, 41, 797-800.

Eren, T. and Güner, E. (2008). "A Bicriteria Flow Shop Scheduling with a Learning Effect”, Applied Mathematics and Computation, 32(9), 1719-1733.

Gupta, J.N.D., Ho, J.C. and Webster, S. (2000). "Bicriteria Optimization of the Makespan and Mean Flowtime on Two Identical Parallel Machines", Journal of the Operational Research Society, 51(11), 1330-1339.

Gupta, J.N.D. and Ruiz-Torres, A.J. (2000). "Minimizing Makespan Subject to Minimum Total Flow-Time on Identical Parallel Machines", European Journal of Operational Research, 125, 370-380.

Hu, H., Ng, K.K.H. and Qin, Y. (2016). "Robust Parallel Machine Scheduling Problem with Uncertainties and Sequence Dependent Setup Time”, Scientific Programming, 2016, 1-13.

Improta, G., Perrone, A., Russo, M.A. and Triassi, M. (2019). "Health Technology Assessment (HTA) of Optoelectronic Biosensors for Oncology by Analytic Hierarchy Process (AHP) and Likert Scale", BMC Medical Research Methodology, 19, 140.

Kasımoğlu, S., Demir, G., Yaz, B.P. and Utku, D.H. (2021). "An Application: A Model with Sequence Dependent Setup Times for Parallel Machines for the Die House Station in a White Goods Manufacturing Company", Osmaniye Korkut Ata University Journal of the Institute of Science and Technology, 4(1), 33-44.

Kurttila, M., Pesonen, M., Kangas, J. and Kajanus, M. (2000). "Utilizing the Analytic Hierarchy Process (AHP) in SWOT Analysis - A Hybrid Method and Its Application to a Forest-Certification Case”, Forest Policy and Economics, 1(1), 41-52.

Lee, Y. and Kozar, K.A. (2006). "Investigating the Effect of Website Quality on E-Business Success: An Analytic Hierarchy Process (AHP) Approach", Decision Support Systems, 42(3), 1383-1401.

Lenstra, J.K., Shmoys, D.B. and Tardos, E. (1990). "Approximation Algorithms for Scheduling Unrelated Parallel Machines", Mathematical Programming, 46 (1-3), 259-271.

Liaw, C.F., Lin, Y.K., Cheng, C.Y. and Chen, M. (2003). "Scheduling Unrelated Parallel Machines to Minimize Total Weighted Tardiness", Computer \& Operations Research, 30(12), 1777-1789.

Lin, C.H. and Liao, C.J. (2004). "Makespan Minimization Subject to Flowtime Optimality on Identical Parallel Machines", Computers and Operations Research, 31(10), 1655-1666.

Mohri, S., Masuda, T. and Ishii, H. (1999). "Bi-Criteria Scheduling Problem on Three Identical Parallel Machines", International Journal of Production Economics, 60, 529-536.

Petruni, A., Giagloglou, E., Douglas, E., Geng, J., Leva, M.C. and Demichela, M. (2019). "Applying Analytic Hierarchy Process (AHP) to Choose a Human Factors Technique: Choosing the Suitable Human Reliability Analysis Technique for the Automotive Industry", Safety Science, 119, 229-239.

Saaty, T.L. (1977). "A Scaling Method for Priorities in Hierarchical Structures", Journal of Mathematical Psychology, 15(3), 234-281.

Sarin, S.C. and Hariharan, R. (2000). "A Two Machine Bicriteria Scheduling Problem," International Journal of Production Economics, 65(2), 125-139.

Suresh, V. and Chaudhuri, D. (1996). "Bicriteria Scheduling Problem for Unrelated Parallel Machines", Computers and Industrial Engineering, 30(1), 77-8.

Teknomo, K. (2006). Analytic Hierarchy Process (AHP) Tutorial

Wong, J.K.W. and Li, H. (2008). "Application of the Analytic Hierarchy Process (AHP) in Multi-Criteria Analysis of the Selection of Intelligent Building Systems", Building and Environment, 43(1), 108-125.

Yalaoui, F. and Chu C. (2002). "Parallel Machine Scheduling to Minimize Total Tardiness", International Journal of Production Economics, 76(3), 265-279.

Younas, M., Jaffery, S.H.I., Khan, M., Khan, M.A., Ahmad, R., Mubashar, A. and Ali, L. (2019). "Multi-Objective Optimization for Sustainable Turning Ti6Al4V Alloy Using Grey Relational Analysis (GRA) Based on Analytic Hierarchy Process (AHP)", The International Journal of Advanced Manufacturing Technology, 105, 1175-1188

Zheng, O., Tian, X. and Yang, M. (2019). "The Email Author Identification System Based on Support Vector Machine (SVM) and Analytic Hierarchy Process (AHP)", IAENG International Journal of Computer Science, 46(2), 1-14. 